\title{
Characteristics of Inner Cycle Flow Rate in Internal Circulation (IC) Anaerobic Reactor under Different Conditions by Fluent Method
}

\author{
Yonghong Liu ${ }^{1,}$ a , Runqiang Zhang ${ }^{1, b}$, Yibo Wang ${ }^{2, a}$, Xingfeng $\mathrm{Yu}^{1, \mathrm{c}}$ \\ ${ }^{1}$ College of Environmental and Chemical Engineering, Xi'an Polytechnic University, Xi'an Shaanxi \\ 710048, China \\ ${ }^{2}$ State key Laboratory Base of Eco-hydraulic Engineering in Arid Area, Xi'an University of \\ Technology, Xi'an, Shaanxi, 710048, China. \\ aliuyhxa@hotmail.com
}

Keywords: IC reactor, Fluent, Inner cycle flow rate, Gas-liquid flow

\begin{abstract}
The process of gas-liquid two-phase flow of an IC anaerobic reactor (25L) was simulated by fluent software. Inner Cycle Flow Rate (QIC) under different volume loading rate(OLR), ratios of riser diameter to reactor diameter(Dr/D), ratios of reactor height to diameter (H/D) were investigated respectively. The results showed that: (i) When OLR was $17.28 \mathrm{kgCOD} /\left(\mathrm{m}^{3} \cdot \mathrm{d}\right)$, a maximum value of QIC $\left(0.0099 \mathrm{~m}^{3} / \mathrm{h}\right)$ was reached under conditions of $\mathrm{H} / \mathrm{D}(5), \mathrm{Dr} / \mathrm{D}(0.081)$. A empirical correlation of QIC and biogas production was gained by fitting analysis; (ii)When Dr/D was 0.081 , a maximum value of $\mathrm{QIC}\left(0.0079 \mathrm{~m}^{3} / \mathrm{h}\right)$ was reached under conditions of $\mathrm{OLR}\left(11.52 \mathrm{kgCOD} /\left(\mathrm{m}^{3} \cdot \mathrm{d}\right)\right), \mathrm{H} / \mathrm{D}(5)$; (iii)When H/D was 3, a maximum value of $\mathrm{QIC}(0.011 \mathrm{~m} 3 / \mathrm{h})$ was reached under conditions of $\operatorname{OLR}\left(17.28 \mathrm{kgCOD} /\left(\mathrm{m}^{3} \bullet \mathrm{d}\right)\right), \mathrm{Dr} / \mathrm{D}(0.081)$.
\end{abstract}

\section{Introduction}

Inner cycle flow rate (QIC) is one key issue for design and calculation of IC reactor. Pereboom ${ }^{[1]}$ et al. proposed their calculation formula of QIC through an iteration procedure based on the principle of internal airlift reactor, however the process was rather complicated, error prone and time consuming.

Numerical simulation by Fluent is an important method on design and operation of biological reactor of wastewater treatment ${ }^{[2]}$. Recently, researchers make a series of studies on anaerobic reactors by this method ${ }^{[3]}$.

Therefore fluent technology will be used to study 2-dimensional distribution of gas-liquid two-phase flow in an IC reactor, QIC under different OLR, Dr/D and H/D will be investigated in this paper. It is expected that it can provide much information for design and controlling operation of IC reactor.

\section{Numerical simulation}

\section{Simulation object}

The simulation was done in an IC reactor (volume $25 \mathrm{~L}$, height $0.691 \mathrm{~m}$, diameter $0.185 \mathrm{~m}$ ). A three-phase separator was mounted at $0.155 \mathrm{~m}$ from top of the reactor. The equipment structure was shown in Fig. 1

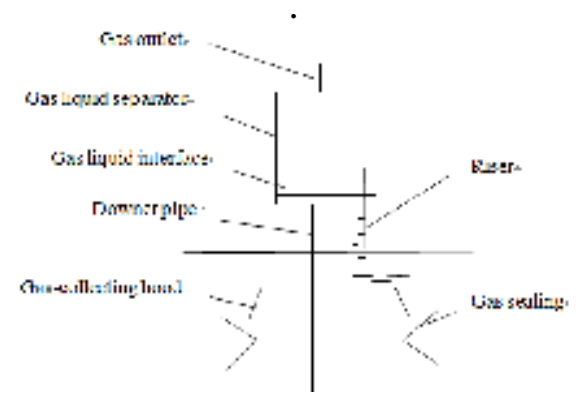

Fig. 1. Structural diagram of simulation object 


\section{Continuity equation}

The mixture momentum equation was modeled as:

$$
\frac{\partial}{\partial}\left(\varphi_{k} p_{k}\right)+V \cdot\left(\varphi_{k} p_{k} \nu_{k}\right)-0
$$

\section{Model parameters}

The physical model was meshed with non-structured grid by CFD code fluent6.3 GAMBIT preprocessor program and grid-independence was validated. When the grid was implemented with a total number of 28230 cells, local gas holdup and upflow velocity in riser began to stabilize with increasing of grid numbers. At that moment it was sufficient to obtain independent result and meet the demand of computation precision.

The pressure-based solver was used in 2-dimension unsteady computational model. Time step size was equal to 0.0003 . When all variable values was less than $1 \times 10^{-3}$ and average rate of liquid in riser reached a constant value with increasing of time, solutions was convergent. The pressure-velocity coupling was obtained by using SIMPLEC algorithm; the first order upwind was performed to solve momentum equation, volume fraction equation and turbulent kinetic energy equation; a standard no-slip boundary condition was applied to all walls.

Boundary conditions: inlet was modeled with a velocity-inlet; top surface of reactor was modeled as pressure-outlet. All other solid surfaces were defined by wall boundary.

Initial conditions: liquid velocity was zero, gas volume fraction was 1.0 and others we reset as default values. Simulation object filled with water under air-water interface.

Operation conditions we selected was as follows: influent COD concentration was $4000 \mathrm{mg} / \mathrm{L}$, COD removal rate $95 \%$ and temperature $35^{\circ} \mathrm{C}$. The selected ranges of simulation parameters were shown in Table 1.

Table 1 Selection range of parameters influent simulation

\begin{tabular}{cccc}
\hline $\begin{array}{c}\text { Inflow } \\
\left(\mathbf{m}^{\mathbf{3}} \cdot \mathbf{d}^{-\mathbf{1}}\right)\end{array}$ & $\begin{array}{c}\text { OLR } \\
\left(\mathbf{k g C O D} \cdot \mathbf{m}^{-\mathbf{3}} \mathbf{d}^{-\mathbf{1}}\right)\end{array}$ & $\mathbf{D}_{\mathbf{r}} / \mathbf{D}$ & H/D \\
\hline 0.06 & 8.64 & 0.0032 & 3 \\
0.07 & 10.08 & 0.0049 & 4 \\
0.08 & 11.52 & 0.0065 & 5 \\
0.09 & 12.96 & 0.0081 & 6 \\
0.1 & 14.40 & 0.0097 & 7 \\
0.11 & 15.84 & 0.114 & $/$ \\
0.12 & 17.28 & $/$ & $/$ \\
0.13 & 18.72 & $/$ & $/$ \\
0.14 & 20.16 & $/$ & $/$ \\
\hline
\end{tabular}

\section{Results and discussion}

\section{Relationship between QIC and OLR}

OLR was one main parameter of IC reactor. Gas production increased with increasing of OLR, which bring about the change of QIC. When $\mathrm{D}_{\mathrm{r}} / \mathrm{D}$ and $\mathrm{H} / \mathrm{D}$ was 0.081 and 5 respectively, $\mathrm{Q}_{\mathrm{IC}}$ under different OLR value $\left(8.64,10.08,11.52,12.96,14.40,15.84,17.28,18.72,20.16 \mathrm{kgCOD} /\left(\mathrm{m}^{3} \cdot \mathrm{d}\right)\right)$ were shown in Fig.2. 


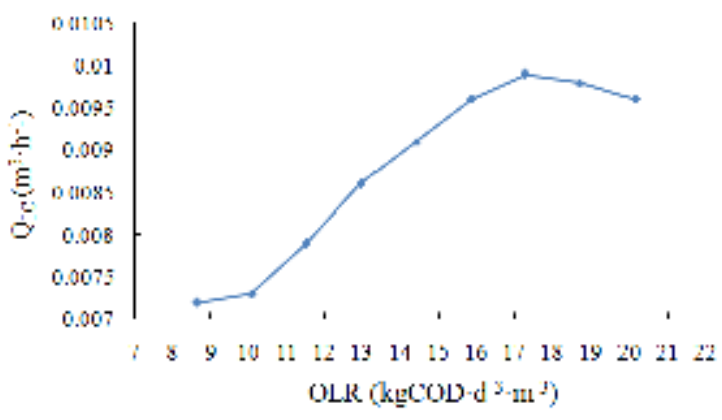

Fig. 2. $\mathrm{Q}_{\mathrm{IC}}$ under different OLR

According to Fig. 2, it was shown that the QIC increased firstly and then declined with increasing of OLR. When OLR increased from $8.64 \mathrm{kgCOD} /\left(\mathrm{m}^{3} \cdot \mathrm{d}\right)$ to $17.28 \mathrm{kgCOD} /\left(\mathrm{m}^{3} \cdot \mathrm{d}\right)$, Q IC reached the peak of $0.0099 \mathrm{~m}^{3} / \mathrm{h}$. But when OLR increased to $20.16 \mathrm{kgCOD} /\left(\mathrm{m}^{3} \cdot \mathrm{d}\right)$, QIC decreased to $0.0096 \mathrm{~m}^{3} / \mathrm{h}$.

The reason of this phenomenon is that generally gas production was proportional to OLR in same

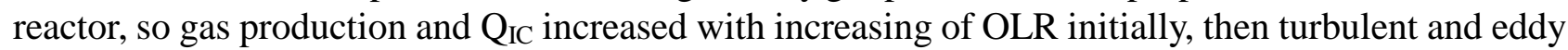
current enhanced with increasing of circulation resistance. When density of mixture in riser decreased to a critical value, upward flow appeared fracture and then $\mathrm{Q}_{\text {IC }}$ decreased ${ }^{[4]}$.

\section{Correlation between QIC and biogas production}

The results of $\mathrm{Q}_{\mathrm{IC}}(\mathrm{Y})$ under different OLR (Fig. 2.) were shown in Table 2.

Table 2 Relationship between gas yield $(\mathrm{X})$ and $\mathrm{Q}_{\mathrm{IC}}(\mathrm{Y})$

\begin{tabular}{ccc}
\hline $\begin{array}{c}\text { OLR } \\
\left(\mathrm{kgCOD} \cdot \mathrm{m}^{-3} \mathrm{~d}^{-1}\right)\end{array}$ & $\begin{array}{c}\mathrm{X} \\
\left(\mathrm{L} \cdot \mathrm{h}^{-1}\right)\end{array}$ & $\begin{array}{c}\text { Y by simulating } \\
\left(\mathrm{L} \cdot \mathrm{h}^{-1}\right)\end{array}$ \\
\hline 8.64 & 2.84 & 7.16 \\
10.08 & 3.32 & 7.31 \\
11.52 & 3.79 & 7.89 \\
12.96 & 4.27 & 8.60 \\
14.40 & 4.74 & 9.12 \\
15.84 & 5.21 & 9.60 \\
17.28 & 5.69 & 9.89 \\
18.72 & 6.16 & 9.84 \\
20.16 & 6.64 & 9.65 \\
\hline
\end{tabular}

The correlation fitted between $\mathrm{Y}$ and biogas production $(\mathrm{X})$ in Table 2 was as follow by fitting analysis:

$$
\mathrm{Y}=13.87-0.142 \mathrm{X}^{3}+1.8 \mathrm{X}^{2}-6.43 \mathrm{X}
$$

According to above regression result, biogas of per cubic meter could lift $1.4 \sim 2.4 \mathrm{~m}^{3}$ liquid to three-phase separator. These were very in accordance with related experimental research and engineering practices, their results showed that biogas of per cubic meter could lift $1 \sim 2 \mathrm{~m}^{3}$ liquid to three-phase separator.

\section{Inner Cycle Flow Rate under different Dr/D}

Related research ${ }^{[5]}$ based on different riser diameters had shown that different gas-liquid mixing proportion could be adjusted by varying riser diameter appropriately, then density of mixtures could be maintained in a reasonable range and recycling process could be kept on.

When OLR and H/D was $11.52 \mathrm{kgCOD} /\left(\mathrm{m}^{3} \cdot \mathrm{d}\right)$ and 5 respectively, QIC and average gas holdup in riser under different $\mathrm{D}_{\mathrm{r}} / \mathrm{D}$ value $(0.032,0.049,0.065,0.081,0.097,0.114)$ were shown in Fig. 3. 


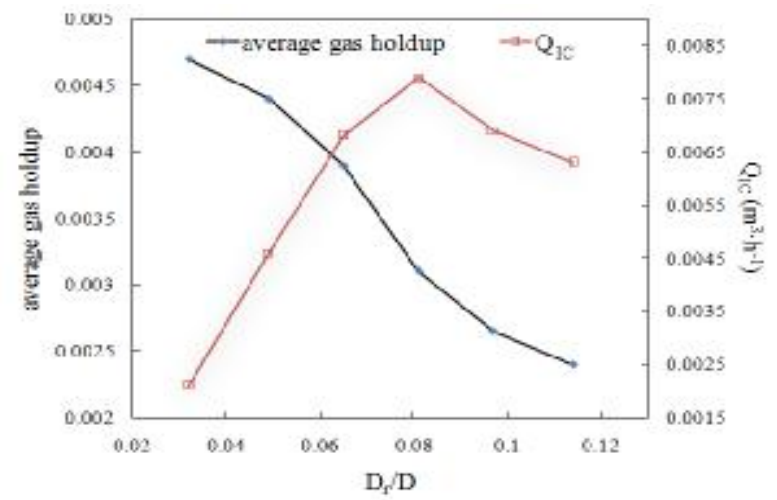

Fig.3. Average gas holdup in riser and $\mathrm{Q}_{\mathrm{IC}}$ under different $\mathrm{D}_{\mathrm{r}} / \mathrm{D}$

Fig. 3 showed that $\mathrm{Q}_{\mathrm{IC}}$ increased from $0.0021 \mathrm{~m}^{3} / \mathrm{h}$ to $0.0079 \mathrm{~m}^{3} / \mathrm{h}$ with $\mathrm{D}_{\mathrm{r}} / \mathrm{D}$ increasing from 0.032 to 0.081 . Then $\mathrm{Q}_{\text {IC }}$ decreased from $0.0079 \mathrm{~m}^{3} / \mathrm{h}$ to $0.0063 \mathrm{~m}^{3} / \mathrm{h}$ with $\mathrm{D}_{\mathrm{r}} / \mathrm{D}$ increasing from 0.081 to 0.114 . The results indicated that the $\mathrm{Q}_{\text {IC }}$ increased firstly and then declined as flow area of mixture increased. Meanwhile average gas holdup in riser decreased from 0.0046 to 0.0024 , when $\mathrm{D}_{\mathrm{r}} / \mathrm{D}$ was adjusted from 0.032 to 0.114 . The reason of this phenomenon is that drag of internal circulation flow decreased and apart of gas was entrained in cycling by upward flow with increasing of $\mathrm{Dr} / \mathrm{D}$, which led that average gas holdup decreased gradually in riser ${ }^{[6]}$. When $\mathrm{D}_{\mathrm{r}} / \mathrm{D}$ was 0.081 , $\mathrm{Q}_{\mathrm{IC}}$ reach maximum value of $0.0079 \mathrm{~m}^{3} / \mathrm{h}$. It means that recommended value of $D_{\mathrm{r}}$ in this reactor is $15 \mathrm{~mm}$.

Liquid velocity field under different H/D value $(3,5,7)$ were shown in Fig. 4. Arrow direction represented moving direction of liquid and color represented velocity magnitude of liquid.

a

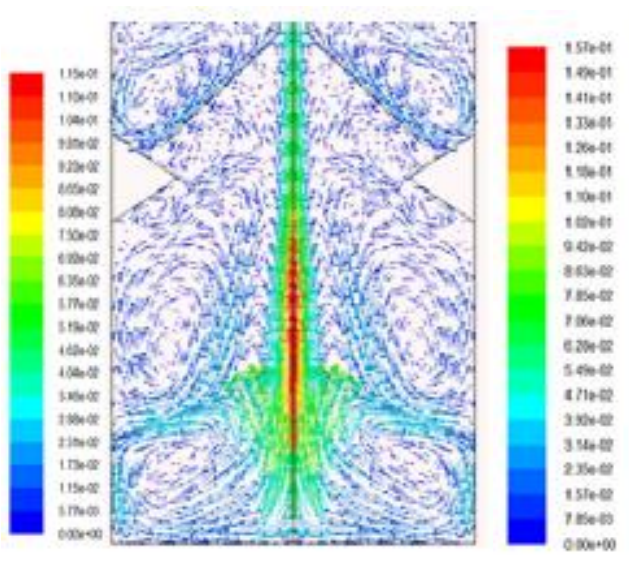

b

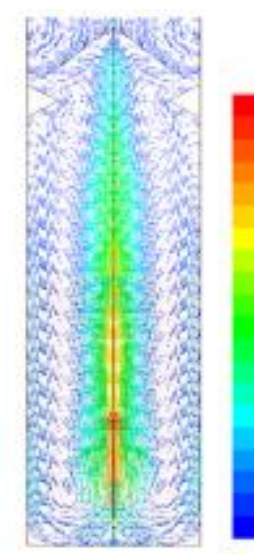

c

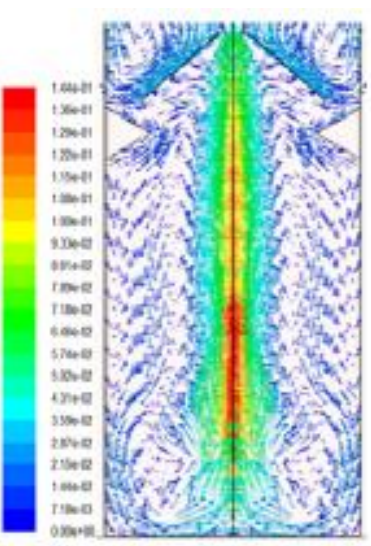

Fig.5 Liquid velocity vectors under different H/D. (a) $\mathrm{H} / \mathrm{D}=3$, (b) $\mathrm{H} / \mathrm{D}=5$, (c) $\mathrm{H} / \mathrm{D}=7$.

When H/D is 3, 5, 7 respectively, there were significant difference in characteristics of back mixing and liquid velocity in riser as shown in Fig. 4. Fig. 4a showed that two large vortexes formed at the bottom of the reactor and back mixing phenomenon was most observable which will be helpful to the hydraulic conditions in the reactor; Fig. 4b showed that two weaker vortexes formed and weaker back mixing was found; Fig. $4 \mathrm{c}$ showed that weakest vortexes formed and weakest back mixing was found. Liquid velocities in riser from high to low were as follows: Fig. 4 b, a, c. In conclusion, the hydraulic mixing characteristics of the reactor were best and liquid velocity in riser was higher when $\mathrm{H} / \mathrm{D}$ was 3 in three different situations.

There were two principle reasons about the above phenomenon ${ }^{[7]}$ : (1) Gas lift function would be decreased when the energy consumption of internal circulation increased; (2) Massive gas did not outflow in time so as to increase the pressure in gas-collecting hood, which resulted in decreasing of pressure difference between the both sides of riser.The first IC reactor (1989) was built in DenBdsch of Netherlands, which volume and H/D was $970 \mathrm{~m}^{3}$ and 3 respectively ${ }^{[8]}$; an IC reactor built in Doosendaal of Netherlands was used to treat chicory wastewater, which volume and H/D was $1100 \mathrm{~m}^{3}$ and 2.8 respectively ${ }^{[9]}$; an IC reactor built in Shanghai of China was used to treat brewery wastewater, 
which volume and H/D was $400 \mathrm{~m}^{3}$ and 4 respectively ${ }^{[10]}$.

According to our simulation results, optimum value of H/D by calculating results was 3, which were very in accordance with above engineering practices.

\section{Conclusions}

In this paper process of gas-liquid two-phase flow in IC reactor $(25 \mathrm{~L})$ was successfully simulated by fluent method. The change of $\mathrm{Q}_{\text {IC }}$ under different operation conditions (inflow and influent COD concentration) is investigated and correlation between $\mathrm{Q}_{\text {IC }}$ and biogas production was gained, which will provide much help for controlling operation of IC reactor. Meanwhile $\mathrm{Q}_{\mathrm{IC}}$ under different $\mathrm{D}_{\mathrm{r}} / \mathrm{D}$ and $\mathrm{H} / \mathrm{D}$ is investigated in this paper, which will provide technical means for optimal structure design of IC reactor (such as riser diameters, H/D).

\section{Nomenclature}

$\mathrm{C}_{\mathrm{D}} \quad$ drag coefficient, dimensionless

$\mathrm{D}$ reactor diameter, $\mathrm{m}$

$\mathrm{F} \quad$ interaction force between phases, $\mathrm{N}$

f drag coefficient, dimensionless

$\mathrm{H}$ height of reactor, $\mathrm{m} \quad \mathrm{K}_{\mathrm{pk}}$

OLR volume loading rates, $\mathrm{kgCOD} /\left(\mathrm{m}^{3} \cdot \mathrm{d}\right)$

$\mathrm{R}_{\mathrm{e}} \quad$ Reynolds number, dimensionless

$v_{\mathrm{m}} \quad$ velocity of mixture, $\mathrm{m} / \mathrm{s}$

$\mu \quad$ molecular dynamic viscosity, $\mathrm{Pa} \cdot \mathrm{s}$

$\rho \quad$ density, $\mathrm{kg} / \mathrm{m}^{3}$

$\overline{\bar{\tau}} \quad$ Reynolds-stress tensor, $\mathrm{N} / \mathrm{m}^{2}$

$\varphi \quad$ volume fraction, dimensionless

Subscripts

g gas $\mathrm{k} \quad \mathrm{k}$-th phase $\mathrm{L} \quad$ liquid $\quad \mathrm{p} \quad \mathrm{p}$-th phase

\section{Acknowledgements}

This work was financially supported the National Natural Science Foundation of China(No.21176197), Science and Technology Innovation Project of Shaanxi Province in China (No. 2011KTZB03-03-01), Science and Technology Development Program of Shaanxi Province in China (Grant No. 2008k07-14) for their support of this study.

\section{References}

[1] Pereboom, T.H.F and Vereijken, T.L.F.M: Water Sci. Tech. Vol.30 (1994), p. 9.

[2] Wang, X., Ren, N.Q and Ding, J: Int. J. Hydrogen Energy. Vol.34 (2009), p.9686.

[3] Ruttithiwapanich, T., Songkasiri, W and Ruenglertpanyakul, W; IERI Procedia. Vol. 5 (2013), p.245.

[4] Muthanna, H.A and Luo, H.P: Chem. Eng. Sci. Vol. 66 (2011), p.907.

[5] Amooghin, A.E, Jafari, S and Sanaeepur, H.C et al: Appl. Math. Model. Vol.38 (2014), p. 4574.

[6] Van Baten, J.M., Ellenberger, J and Krishna, R: The Canadian Journal of Chemical Engineering. Vol. 81(2003), p.660.

[7] Thorat, B.N, Shevade, A.V and Bhilegaonkar, K.N.et al: Trans IChemE. Vol.76 (1998), p.823.

[8] Pereboom, T.H.F:Water Sci. Tech. Vol. 30 (1994), p.211.

[9] Habets, H.A: Water Sci. Tech. Vol. 35 (1997), p.189-197.

[10] He, X.J: China Water and Wastewater. Vol. 23 (1997), p.26. 